\title{
Effects of Thermal Cycling and Thermal Stability on 2G HTS Conductors Pancake Coils
}

\author{
Ana B. Nuñez-Chico, Elena Martínez, Luis A. Angurel, Rafael Navarro
}

\begin{abstract}
Degradation of superconducting critical currents of 2G-HTS coils may appear upon thermal cycling due to the tensile stress differences of its elements that induce increasing tape damages. We report on the thermal cycling and thermal stability effects of round, epoxy impregnated pancake coils under two cooling conditions (liquid nitrogen and conduction cooling). Thermal stability has been analyzed by measuring the quench development and propagation. Minimum quench energy values and longitudinal and radial propagation velocities are reported. The influence of different epoxy impregnations and number of turns in the thermal cycling effects and quench behavior has been studied.
\end{abstract}

Index Terms-2G-HTS conductors, Quench, Superconducting magnets, Thermal cycling.

\section{INTRODUCTION}

$\mathrm{S}$ ECOND generation high temperature superconductors (2GHTS), based on rare earth elements (RE) $\mathrm{Ba}_{2} \mathrm{Cu}_{3} \mathrm{O}_{7-\mathrm{x}}$, are considered nowadays the best candidates for electric power applications. 2G-HTS tapes allow operating temperatures higher than 1G-HTS conductors, based on $\mathrm{Bi}_{2} \mathrm{Sr}_{2} \mathrm{Ca}_{2} \mathrm{Cu}_{3} \mathrm{O}_{10+x}$, $\mathrm{MgB}_{2}$ wires or low temperature superconductors (LTS). Nevertheless, almost all commercial applications use LTS, and most HTS prototypes have been developed with 1G-HTS. Although the available commercial 2G-HTS conductors reach the superconducting properties required in most electric power applications, some drawbacks need to be solved before their extensive use, particularly those related with their low thermal stability, coil quench protection and thermal cycling degradation [1]. Differences in thermal expansion coefficients between the coil mechanical support, the different 2G-HTS tape components and the binder epoxies may progressively degrade the superconducting properties even resulting in irreversible damages [2], [3].

In order to investigate the effect of thermal cycling in the critical current of 2G-HTS coils, several units fabricated with different epoxy impregnations, numbers of turns and insulation, have been manufactured. The quench development and propagation have also been analyzed experimentally for better understanding of their thermal stability properties.

Manuscript received August 8, 2014, revised October 9, 2014

This work was supported by the Spanish Ministerio de Economía y Competitividad and the European FEDER Program (project MAT201122719) and by the Gobierno de Aragón (research group T12).

All authors are with the Instituto de Ciencia de Materiales de Aragón (CSIC - Universidad de Zaragoza), Dpto. Ciencia y Tecnología de Materiales y Fluidos, C/ María de Luna 3, 50018 Zaragoza (Spain).

e-mails: elenamar@unizar.es
Moreover, thermal cycling effects on these coils have been studied. Slow and fast cooling downs and warming up cycles have been performed, and the critical current, $I_{c}$, was measured after each cooling, analyzing its homogeneity along the coil.

\section{EXPERIMENTAL DETAILS}

\section{A. Fabrication and characterization coils}

The coils have been fabricated using $2 \mathrm{G}$-HTS commercial tapes $(100 \mu \mathrm{m} \times 4 \mathrm{~mm})$ from SuperPower Inc. The tapes have $50 \mu \mathrm{m}$ thick Hastelloy ${ }^{\circledR}$ substrate, $\approx 1 \mu \mathrm{m}$ superconducting layer, $2 \mu \mathrm{m} \mathrm{Ag}$ layer on top of it and $20 \mu \mathrm{m} \mathrm{Cu}$ coating around the tape. The electrical insulation was reached using $50 \mu \mathrm{m}$ thick $\approx 4 \mathrm{~mm}$ wide Kapton ${ }^{\circledR}$ tape in two different arrangements: i) By spiral wrapping around the 2G-HTS tape, with $\approx 30 \%$ overlap between layers ii) By gluing it along one side of the tape. The thickness of insulated tapes was $0.30 \mathrm{~mm}$ for the first case and $0.15 \mathrm{~mm}$ for the second one.

Five single pancake round coils with common $65 \mathrm{~mm}$ inner diameter, number of turns between 10 and 30 and height given by the tape width have been fabricated with the characteristics given in Table I. Coils A, B, and C were impregnated turn to turn with Stycast ${ }^{\circledR} 1266$ during winding. Coil D was dry wound and subsequently impregnated with Stycast ${ }^{\circledR} 2850 \mathrm{FT}$, but due to its high viscosity (58 $\mathrm{Pa} \cdot \mathrm{s}$ ), just the external surfaces were covered. Coil E was dry wound and impregnated afterwards with Loctite $^{\circledR} 420$. Due to its low viscosity $(\sim 0.002 \mathrm{~Pa} \cdot \mathrm{s})$ it enables full impregnation by capillarity. In all cases, a constant tensile stress of $2 \mathrm{~N}$ was applied to the tape during winding, which were done on a PTFE former, with the first turn weakly bonded to it for easy coil extraction when the epoxy is dry.

TABLE I

CHARACTERISTICS OF THE MEASURED PANCAKE COILS

\begin{tabular}{lccccc}
\hline \hline Coil & $\mathrm{A}$ & $\mathrm{B}$ & $\mathrm{C}$ & $\mathrm{D}$ & $\mathrm{E}$ \\
\hline$N($ turns $)$ & 30 & 10 & 10 & 10 & 20 \\
$\Phi_{\text {in }}(\mathrm{mm})$ & 65 & 65 & 65 & 65 & 65 \\
$\Phi_{\text {out }}(\mathrm{mm})$ & 87 & 72 & 72 & 72 & 73 \\
Winding & Wet & Wet & Wet & Dry & Dry \\
Binder & 1266 & 1266 & 1266 & $2850 \mathrm{FT}$ & Loctite 420 \\
$I_{c}(\mathrm{~A})$ tape & 101 & 101 & 101 & 101 & 94 \\
$I_{c}(\mathrm{~A})$ coil & 48 & 64 & 65 & 68 & 58 \\
\hline \hline
\end{tabular}

Coils A, B, C, and D were electrically insulated with Kapton ${ }^{\circledR}$ wrapped around the $2 \mathrm{G}$-tape and coil E with a Kapton ${ }^{\circledR}$ layer between turns. $\Phi_{i n}$ and $\Phi_{\text {out }}$ are, respectively the inner and outer pancake coil diameters, Binders 1266 and $2850 \mathrm{FT}$ are Stycast ${ }^{\circledR}$ epoxy resins. $I_{c}$ values at $77 \mathrm{~K}$ and zero external magnetic fields. 
To measure the voltage and temperature in different parts of the coil, thin $\mathrm{Cu}$ sheets, $75 \mu \mathrm{m}$ thick and $4 \mathrm{~mm}$ wide, were soldered to the tape during winding, as well as $\mathrm{Cu}$ feeding contacts, $0.75 \mathrm{~mm} \times 30 \mathrm{~mm} \times 150 \mathrm{~mm}$, to the coil ends.

The self-field critical currents, $I_{\mathrm{c}}$, collected in Table I, have been determined at $77 \mathrm{~K}$ with the usual $1 \mu \mathrm{V} / \mathrm{cm}$ criterion. On the tapes used for coils A, B, C, and D, $I_{\mathrm{c}}=101 \mathrm{~A}$, and for coil $\mathrm{E}, I_{\mathrm{c}}=94 \mathrm{~A}$. For the coils, the same criterion, but with the total length of the wound tape, was used leading to lower $I_{\mathrm{c}}$ values, which roughly agree with our estimations derived from the $I_{\mathrm{c}}(B)$ of the tape given by the manufacturer, and by taking into account the self field on each turn.

In order to detect inhomogeneities and the presence of local damages, some voltage taps were added to measure the critical current of different sections of the coils. The critical current measured in the inner section, between turns 1 to $N_{0} / 2$ (where $N_{0}$ is the mid turn of each coil), reaches minimum values, 96\%-97\% of the coil $I_{\mathrm{c}}$. The central section, from turns $N_{\delta} / 2$ to $3 N_{0} / 2$, shows the highest values, $110 \%-116 \%$, whereas the outer section, from $3 N_{0} / 2$ to $2 N_{0}$, reaches intermediate values, $102 \%-105 \%$.

\section{B. Thermal cycling}

Fast and slow cooling down and warming up cycles have been performed. For slow cooling down rates, the coils were placed inside a cryostat at room temperature. Liquid nitrogen, $\mathrm{LN}_{2}$, was slowly transferred to it taking about 2 hours to reach full coil immersion. For fast cooling down rates, the coils were immersed in a $\mathrm{LN}_{2}$ filled cryostat. In both cases, after thermal stabilization at $77 \mathrm{~K}$ the coil was energized to measure $I_{\mathrm{c}}$. Slow warming up temperature rates were obtained by slow $\mathrm{LN}_{2}$ evaporation with the coil inside the cryostat, taking several hours to reach room temperature. Fast warming up rates were reached by removing the coil from the cryostat at $77 \mathrm{~K}$ to room temperature and drying with a hot air convector to avoid ice formation. A sequence of three to five slow rate cooling down and warming up cycles was done, followed by sets of fast rate cycles.

\section{Quench measurements}

Quench experiments were performed in vacuum with the coils cooled by thermal conduction using a cryocooler and a temperature Lakeshore 331 controller. In order to reach good thermal contact, the coils were glued with Stycast 2850 FT epoxy to an aluminum disc, which was attached to the cryocooler cold finger to ensure good thermal contact. Moreover, the coil current feeding contacts were thermally anchored to the second stage of the cryocooler cold head to minimize incoming heat from the current leads and Joule electric resistance. Three thermocouples were soldered in each coil, one near the heater and the other two near the current contacts.

During quench measurements, energy pulses, $Q_{\mathrm{ini}}$, were deposited to the conductor by applying to the heater, voltage pulses of fixed amplitude, $V_{\mathrm{p}}$, and different duration, $t_{\mathrm{p}}$, with the coils carrying DC currents $I<I_{\mathrm{c}}\left(T_{0}\right)$. A small strain gage, glued to the tape surface using $\mathrm{GE}^{\circledR}$ varnish [4], was used as

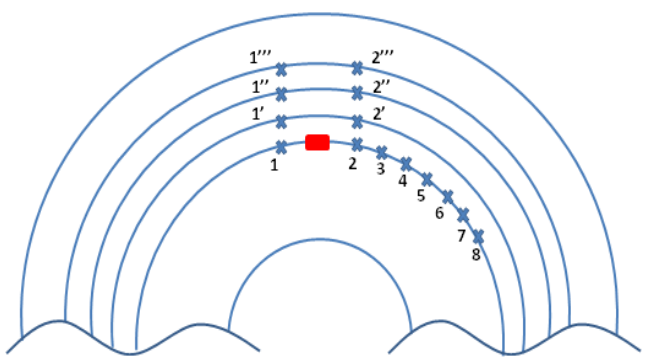

Fig. 1. Schematic distribution of voltage taps used in the quench analysis of the pancake coils. The rectangle (in red) corresponds to the heater, which is placed in the mid turn of the coil.

heater, which is $3 \mathrm{~mm}$ long, $2 \mathrm{~mm}$ wide and $0.4 \mathrm{~mm}$ thick and has an electric resistance of $120 \Omega$.

The schematic distribution of the voltage taps within the coil for quench measurements can be seen in Fig. 1. The heater was placed in the mid turn, $N_{0}$, at equal distances from voltage taps 1 and 2 . Pairs of radially aligned voltage taps $\left(1^{\prime}, 2^{\prime}\right),\left(1^{\prime \prime}, 2\right.$ ''), and (1',',2'”), were located at $N_{0}+1, N_{0}+2$ and $N_{0}+3$ outsider turns, respectively, in order to detect the radial quench propagation velocity, or propagation between turns. Additionally, in the mid turn, five voltage taps $3,4, \ldots, 8$, were soldered to measure the tangential quench propagation. The voltage taps were simultaneously recorded using a data acquisition device (DAQ).

\section{RESULTS AND DISCUSSION}

\section{A. Effect of thermal cycling}

Thermal cycling effects have been studied at $77 \mathrm{~K}$ by measuring the $V(I)$ curves on different parts of the coil. From these curves we have obtained the coil critical current $I_{\mathrm{c}}$ as well as the exponent $n$ that for $I>I_{\mathrm{c}}$ relates voltage and current by fitting the $V \sim I^{n}$ dependence. The results of normalized $I_{\mathrm{c}}$ values on coils A and B as a function of the number of cycles $\left(N_{\text {cycles }}\right)$ and for different zones are displayed in Fig. 2.

Despite the different binder and insulation that have been used, coils B, C, D, and E, with less number of turns $(N<20$

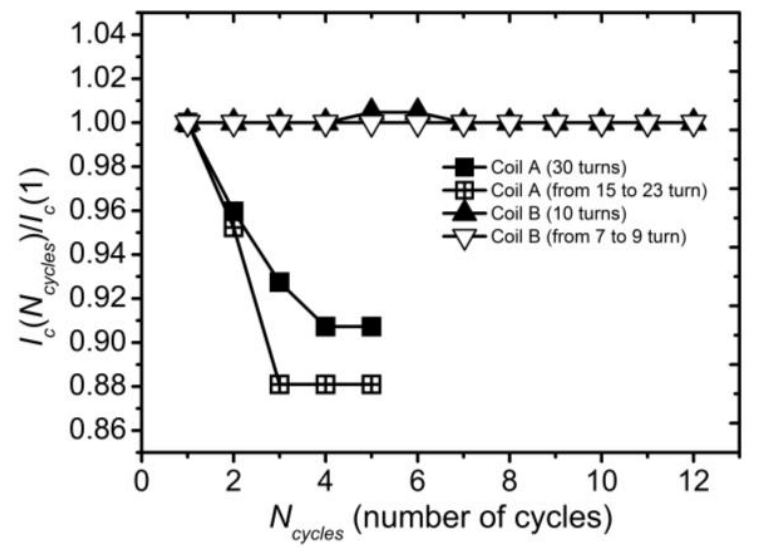

Fig. 2. Evolution of the reduced coil critical current values $I_{\mathrm{c}}\left(N_{\text {cycles }}\right) / I_{\mathrm{c}}(1)$ deduced form experimental $V(I)$ curves with thermal cycles on A and B coils and a section of both coils. Coils C, D, and E, which do not degrade under thermal cycling are not included. 
turns) and $n$ values ranging between 23 and 26 do not show any sign of degradation under three slow and nine fast rate cooling and warming cycles. However, for coil $\mathrm{A}(N=30)$, the coil degradation starts with the first slow rate cycle. No fast rate cycles were done in this coil. The damaged section is found between turns 15 and 23. For $N_{\text {cycles }}=1$, this zone had $I_{\mathrm{c}}$ $=42 \mathrm{~A}$ and $n=7$, whereas the overall coil had $I_{\mathrm{c}}=48 \mathrm{~A}$ and $n$ $=14$, and the undamaged sections had $I_{\mathrm{c}}=52 \mathrm{~A}$ and $n=24$.

\section{B. Minimum quench energies $(M Q E)$ and propagation quench velocities $\left(v_{p}\right)$}

The minimum quench energy $(M Q E)$ was obtained applying voltage pulses of maximum amplitude and different durations to the heater and analyzing the tap's voltage evolution. Below the $M Q E$ value, the system (measured voltages) recovers the initial conditions, whereas above this value the disturbance causes the irreversible superconductor to normal transition on a zone that continuously enlarges originating the quench propagation to the full coil.

The $M Q E$ values measured at $70 \mathrm{~K}$ on coils $\mathrm{C}$ and $\mathrm{E}$ are compared in Fig. 3. Both coils have similar dimensions despite their different number of turns. This is because of the thicker electrical insulation layer used in coil $\mathrm{C}$. For equal conditions of temperature and reduced currents, $I / I_{c}$, the higher $M Q E$ values of coil $\mathrm{E}$ could be due to its lower thermal resistance between turns. The $M Q E$ values of coil $\mathrm{C}$ measured at other temperatures, $77 \mathrm{~K}$ and $63 \mathrm{~K}$, which range between 150 and $250 \mathrm{~mJ}$ are also displayed in Fig. 3. These values show weak temperature dependence, as expected by the small thermal conductivity and specific heat changes of the used composite materials in this range of temperatures. It should be remarked that, in this temperature range, the coil's $M Q E$ values increases with temperature in opposition with the observed behavior on straight pieces of the same $\mathrm{Cu}$-stabilized tapes [5], [6]. Nevertheless, other authors have already observed this unexpected behavior on similar $2 \mathrm{~mm}$ wide tapes without thermal stabilizer [7].

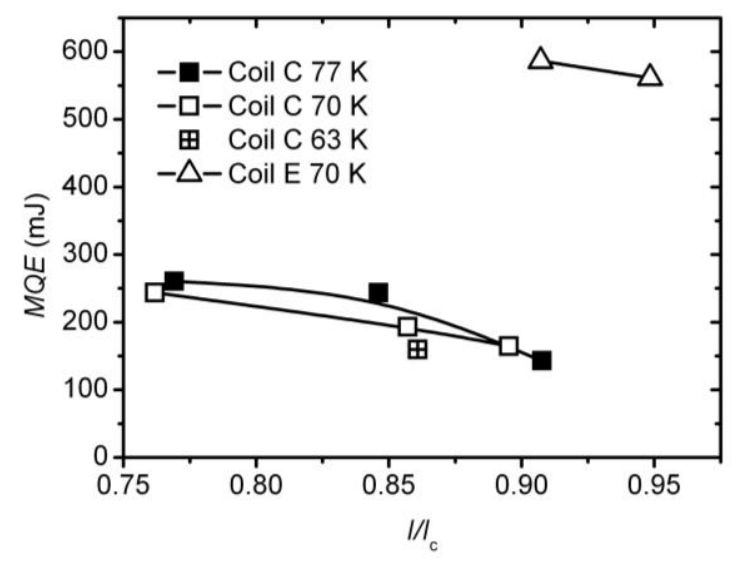

Fig. 3. $M Q E$ as a function of reduced current $I / I_{c}$ measured for coils $\mathrm{C}$ and $\mathrm{E}$ at different temperatures. $I_{c}$ is the critical current of the coil, which is: $65 \mathrm{~A}$ $(77 \mathrm{~K}), 105 \mathrm{~A}(70 \mathrm{~K})$, and $151 \mathrm{~A}(63 \mathrm{~K})$ for coil C and $97 \mathrm{~A}(70 \mathrm{~K})$ for coil E. The duration of the heat pulses, $t_{\mathrm{p}}$, ranges from 85 to $155 \mathrm{~ms}$ for coil C and from 335 to $350 \mathrm{~ms}$ for coil E.
As the current has been scaled with the coil critical current and the local $I_{c}$ is higher around the heater, it is not possible to measure $M Q E$ at $I / I_{c}$ values close to 1 , since the quench would be originated at regions where the applied current overpass the local $I_{c}$ value, instead of being developed around the heater by the income energy.

During quench experiments at $63 \mathrm{~K}$ and $I / I_{c}=0.86(I=130$ A), coil $\mathrm{C}$ was irreversibly damaged. The maximum total coil voltage was $2.5 \mathrm{~V}$ and the maximum voltage between taps 1 and 2 was $0.36 \mathrm{~V}$. A small kink $\approx 5 \mathrm{~mm}$ long was produced in the inner turn closer to the heater. In order to analyze the damage extension, the coil was cut and the turns separated to measure its critical currents. We observed that a length of about $5 \mathrm{~mm}$ around the kink was seriously damaged, with a critical current of only $1 \mathrm{~A}$. Moreover, near this zone the tape had $I_{c}$ between 30 and $58 \mathrm{~A}$, whereas the $I_{\mathrm{c}}$ values of all the other turns did not show any degradation. The observation of very localized damages produced by quench agrees with reported results, see for example [8], and indicates the difficulties for coil quench protection. In our experiment, the power supply voltage was limited to $2-3 \mathrm{~V}$, switching off the current 2-4 seconds after the heat pulse, and this procedure was not enough to prevent local damages.

The time evolution of the electric fields $E_{i j}(\mathrm{t})$ measured during a quench on different coil $\mathrm{C}$ turns is showed in Fig. 4, where $E_{i j}=V_{i j} / d_{i j}$, is the average electric field between taps $i$ and $j, V_{i j}$ is the voltage and $d_{i j}$ the distance between them. The displayed results show that by switching on the heater at $t=65$
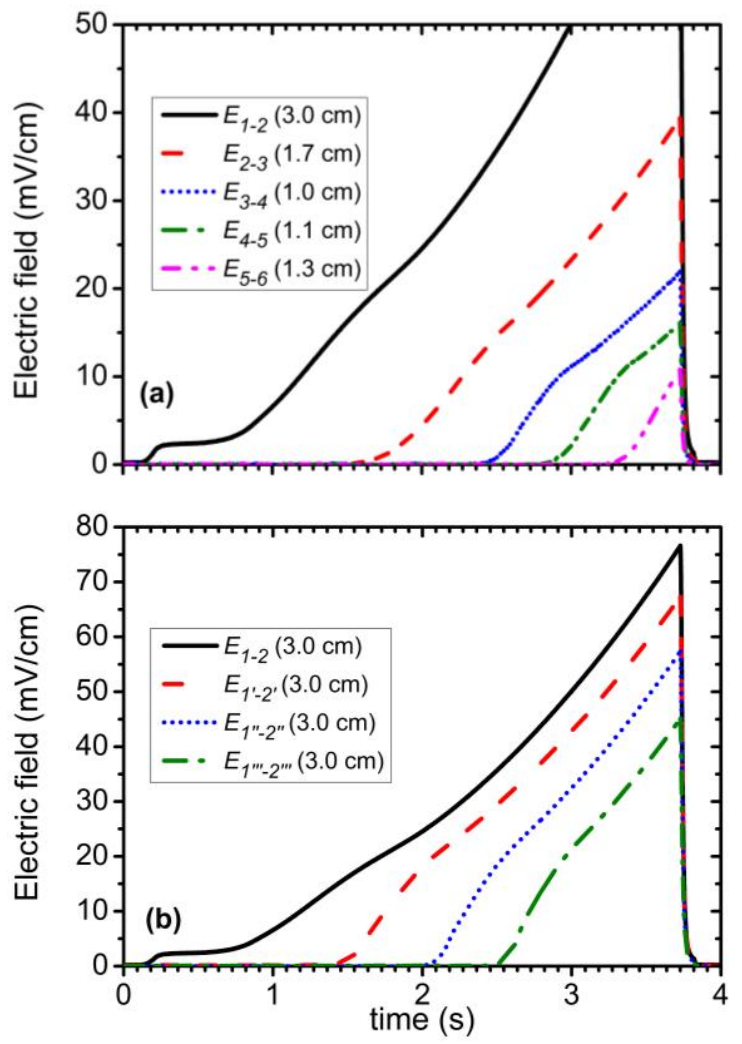

Fig. 4. Electric fields $E_{i j}(t)$ between different tap pairs on coil $\mathrm{C}$ at $70 \mathrm{~K}, I=$ $80 \mathrm{~A}=0.75 I_{c}$ for quench propagation analysis. (a) Tap pairs along the mid turn $N_{0}$, and (b) Tap pairs at $N_{0}+1, N_{0}+2$ and $N_{0}+3$ turns. The tap pair distances are given in parenthesis. 
ms the quench is triggered at $t \approx 0.8 \mathrm{~s}$, and at this time only $E_{12}$ is non zero. Since $d_{12}=3 \mathrm{~cm}$ and the distance between next turns is $0.31 \mathrm{~mm}$, these results indicate that $M P Z$ is shorter than $3 \mathrm{~cm}$ and $0.31 \mathrm{~mm}$ in the tangential and radial directions, respectively. This behavior is observed for all measured operating currents and temperatures. In case of coil E, where the distance between turns is $0.16 \mathrm{~mm}$, a similar behavior has also been observed and in consequence, the $M P Z$ is lower than $3 \mathrm{~cm}$ in the tangential direction and lower than $0.16 \mathrm{~mm}$ in the radial direction.

The tangential and radial quench propagation velocities, $v_{\mathrm{p}}$, for coils $\mathrm{C}$ and $\mathrm{E}$ at $70 \mathrm{~K}$ as a function of the reduced current are plotted in Fig. 5. These values have been obtained from the ratios of corresponding distances with the time delay between subsequent $E_{i j}$ curves, outside the MPZ region. Both, tangential and radial $v_{\mathrm{p}}$ components, are similar for both coils. The radial values are 30-35 times lower. The tangential $v_{\mathrm{p}}$ component ranges are between 25 to $40 \mathrm{~mm} / \mathrm{s}$, which are a factor $\sim 1.5$ lower than the ones measured in similar conditions for the used tapes [5]. This $v_{\mathrm{p}}$ lowering has been also observed in $\mathrm{MgB}_{2}$ conductors and coils [4] and ascribed to the higher coil thermal conductivity and inertia of surrounding insulation layers, epoxy binders and conductors.

Using the effective media approach, the overall thermal conductivity in the radial direction is,

$$
\frac{1}{k_{\perp}} \cong \frac{\lambda_{C C}}{k_{C C \perp}}+\frac{\lambda_{K}}{k_{K}}+\frac{\lambda_{e p}}{k_{e p}},
$$

where $\lambda_{\mathrm{CC}}, \lambda_{\mathrm{K}}$ and $\lambda_{\mathrm{ep}}$ are the coil volume proportions of coated conductors, Kapton insulation and epoxy, respectively, $k_{\mathrm{CC} \perp}$, is the radial thermal conductivity of the 2G-HTS tape and $k_{K}$ and $k_{\text {ep }}$, the thermal conductivities of Kapton ${ }^{\circledR}$ and epoxy binder, respectively. By using eq. (1), with the values collected for $70 \mathrm{~K}$ in Table II, we have estimated the radial thermal conductivities, $k_{\perp} \sim 0.21$ and $0.30 \mathrm{~W} \cdot \mathrm{K}^{-1} \cdot \mathrm{m}^{-1}$ for coils $\mathrm{C}$ and $\mathrm{E}$, respectively.

If we consider the value obtained in [9] for the thermal conductivity in the tangential direction, $k_{/ /}=261 \mathrm{~W} \cdot \mathrm{K}^{-1} \cdot \mathrm{m}^{-1}$, the expected anisotropy [5] would be $\left(k_{/ /} / k_{\perp}\right)^{1 / 2} \sim 35.2$ and 29.5 for coils $C$ and $E$, respectively, which are very similar to

TABLE II

THERMAL CONDUCTIVITIES AND COIL VOLUME PROPORTIONS

\begin{tabular}{lcccc}
\hline \hline & \multicolumn{2}{c}{ Coil C } & \multicolumn{2}{c}{$\begin{array}{c}\text { Coil E } \\
\text { (Loctite 420) }\end{array}$} \\
\hline & $k\left(\mathrm{~W} \cdot \mathrm{K}^{-1} \cdot \mathrm{m}^{-1}\right)$ & $\lambda$ & $k\left(\mathrm{~W} \cdot \mathrm{K}^{-1} \cdot \mathrm{m}^{-1}\right)$ & $\lambda$ \\
Used tape & 18.6 & 0.32 & 18.6 & 0.63 \\
Kapton $^{\circledR}$ & 0.13 & 0.65 & 0.13 & 0.31 \\
Epoxy resin & 0.14 & 0.03 & 0.07 & 0.06 \\
\hline \hline
\end{tabular}

$70 \mathrm{~K}$ thermal conductivities of used tape (radial) [9] , Kapton ${ }^{\circledR}[10]$ and binder resin (estimated from the $300 \mathrm{~K}$ values $k=0.2$ and $0.1 \mathrm{~W} \cdot \mathrm{K}^{-1} \cdot \mathrm{m}^{-1}$, respectively, for Stycast ${ }^{\circledR} 1266$ [11] and Loctite ${ }^{\circledR} 420$ [manufacturer], assuming a $k(T)$ dependence similar to Kapton ${ }^{\circledR}$ ).

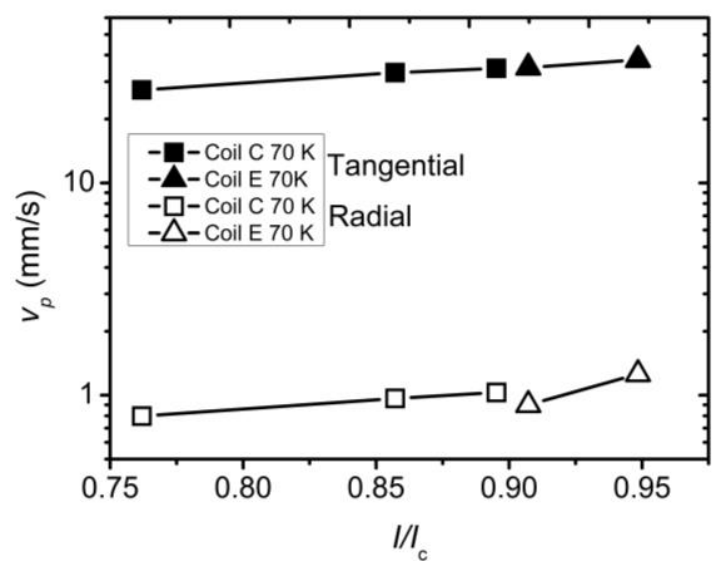

Fig. 5. Quench propagation velocity $\left(v_{p}\right)$ at $70 \mathrm{~K}$ and different $I / I_{c}$ values on coils $\mathrm{C}$ and E. Full and empty symbols indicate tangential and radial directions, respectively.

the values obtained experimentally.

\section{CONCLUSION}

Five round pancake coils were fabricated to investigate the effects of thermal cycling and thermal stability under two cooling conditions, liquid nitrogen and conduction cooling. Thermal cycling on coils with small number of turns, $N \leq 20$, did not affect their superconducting properties, even if different electric insulation epoxies have been used, whereas the coil with $N=30$, is already damaged for the first slow rate temperature cycles. On coil quench measurements the $M Q E$ is affected by the differences in the insulations layers. However, both, tangential and radial $v_{p}$ components, are similar for the coils analyzed and its ratio is in accordance with the expected propagation velocity anisotropy of the coils. One of the coils was damaged locally during the quench measurements, which manifests the difficulty for $2 \mathrm{G}$-HTS coil quench protection.

\section{REFERENCES}

[1] C Senatore et al., "Progresses and challenges in the development of high-field solenoidal magnets based on RE123 coated conductors," Supercond. Sci. Technol., vol. 27, 2014, Art. No 103001.

[2] M. Oomen et al., "Manufacturing and test of 2G-HTS coils for rotating machines: Challenges, conductor requirements, realization," Physica C vol. 482, 2012, pp. 111-118.

[3] T. Takematsu et al., "Degradation of the performance of a YBCO-coated conductor double pancake coil due to epoxy impregnation," Physica $C$, vol. 470, 2010, pp. 674-677.

[4] J. Pelegrin et al., "Experimental and numerical analysis of quench propagation on $\mathrm{MgB}_{2}$ tapes and pancake coils," Supercond. Sci. Technol., vol. 26, 2013, Art. No. 045002.

[5] J. Pelegrin et al., "Numerical and experimental analysis of normal zone propagation on 2G HTS wires," IEEE Trans. Appl. Supercond., vol. 21, Jun. 2011, pp. 3041-3044.

[6] H. Song, K. Gagnon and J. Schwartz, "Quench behavior of conductioncooled $\mathrm{YBa}_{2} \mathrm{Cu}_{3} \mathrm{O}_{7-\gamma}$ coated conductor pancake coils stabilized with brass and cooper," Supercond. Sci. Technol., vol. 23, 2010, Art. No. 065021.

[7] E. A. Young, C. M. Friend and Y. Yang, "Quench characteristics of a stabilizer-Free 2G HTS Conductor," IEEE Trans. Appl. Supercond., vol. 19, no. 3, Jun. 2009, pp. 2500-2503.

[8] D. X. Ma et al., "Degradation analysis of REBCO coils," Supercond. Sci. Technol., vol. 27, 2014, Art. No. 085014. 
[9] M. D. Sumption et al., "Thermal diffusion and quench propagation in YBCO pancake coils wound with $\mathrm{ZnO}$ and Mylar insulations," Supercond. Sci. Technol., vol. 23, 2010, Art. No. 075004.

[10] J. W. Ekin, "Experimental techniques for low temperature measurements," Oxford University Press 2006.

[11] D. H. Tien et al., "Electrical and thermal conductivity of Stycast 1266 epoxy/graphite composites," J. Korean Phys. Soc., vol. 59, no. 4, October 2001, pp. 2760-2764. 